\title{
FLAMMABILITY LIMITS IN FLOWING ETHENE-AIR-NITROGEN MIXTURES: AN EXPERIMENTAL STUDY
}

\author{
J.W. BOLK, N.B. SICCAMA*, K.R. WESTERTERP* \\ Chemical Reaction Engineering Laboratories, Department of Chemical Engineering \\ University of Twente, PO Box 217, 7500 AE Enschede, The Netherlands
}

\begin{abstract}
A large pilot plant was constructed to study the upper flammability limit of ethene-air-nitrogen mixtures under conditions of flow. The gas mixtures flowed through an explosion tube with a length of $3.0 \mathrm{~m}$ and a diameter of $21 \mathrm{~mm}$. An electrically heated wire was used as ignition source. Experiments were performed at pressures of 5 and $10 \mathrm{bar}$, with gas temperatures between 25 and $300^{\circ} \mathrm{C}$ and with the wire fixed horizontally and vertically.

Three different phenomena are observed: negligible reaction, local reaction, and explosion. The negligible reaction region occurs at power supply rates to the wire below a critical value. Above this critical value either a local reaction or an explosion occurs. The critical oxygen concentration which separates the local reaction and explosion regimes depends on the experimental conditions: gas composition, pressure, temperature, wire size and orientation, and gas velocity. An increase in pressure increases the upper flammability limit. Also an increase in temperature causes an increase in the upper flammability limit and the results can be explained by assuming a constant flame temperature.

Moreover, the upper flammability limit is influenced by the gas velocity. Under conditions of flow the explosion region becomes smaller, it shifts to higher oxygen concentrations. In practise this may mean that partial oxidaion reactions can safely be operated at higher oxygen concentrations, provided gas flow rates are kept high.
\end{abstract}

\section{INTRODUCTION}

Partial oxidation reactions are widely used in industry. A typical example is the reaction of ethene to ethene oxide. The stoichiometric mixture of this reaction is explosive and therefore the partial oxidation process must be operated at much leaner conditions. This is achieved by operating above the upper flammability limit with ethene in excess. For a safer and more economical process it is necessary to know the flammability limits precisely in order to operate ethene oxidation plants closer to their flammability limits.

Flammability limits of a particular system of gases are affected by pressure, temperature, direction of flame propagation, ignition source and experimental set-up. Flammability limits are usually determined in closed vessels or explosion tubes, with in most cases a spark as the ignition source, see e.g. Lewis and Von Elbe (1961), Zabetakis (1965), and Lovachev et al. (1973). These results are considered to be also valid under industrial conditions. However, these laboratory experiments differ from industrial operating conditions, regarding the gas flow and the ignition source. Therefore it is questionable whether the results of laboratory experiments can be used for the industrial situation.

For partial oxidation processes the occurrence of sparks as an ignition source is unlikely, because water vapour produced in an oxidation reaction will lead to a good electrical conductivity and prevent accumulation of static electricity. It is more likely that a hot spot will act as an ignition source. Unfortunately different ignition sources lead to large differences in flammability limits, see e.g. Coward and Guest (1927), Cutler (1974) and Detz (1976).

The gas flow affects the heat-transfer rate from the ignition source and therefore affects the ignition of a combustible gas mixture. In flowing systems it is more difficult to ignite an explosive mixture, because of the increased rate of heat removal caused by convection from the hot spot to the surrounding gas. Furthermore, flame propagation is more difficult through a fast flowing system because of the increased level of turbulence and therefore an increased heat transfer from the flame front to the unburnt gas, which may extinguish the flame. Lewis and Von Elbe (1961), Leuckel et al. (1989), Chippett (1993) and Watanabe et al. (1983) all come to the conclusion that the flammability limit is influenced by the degree of turbulence in the gas mixture.

It has also been mentioned that flammability limits in reality differ from those found in laboratory experiments. For example the flammability limit of ammonia and air mixtures depends on the gas velocity, see Ullmann (1981). Siccama and Westerterp (1993) have also demonstrated that the explosion region of ethene-air-nitrogen mixtures, ignited with a hot surface, becomes smaller under conditions of flow.

\footnotetext{
"Currently: ECN, P.O.Box 1 , Petten, the Netherlands

"To whom correspondence should be addressed
} 

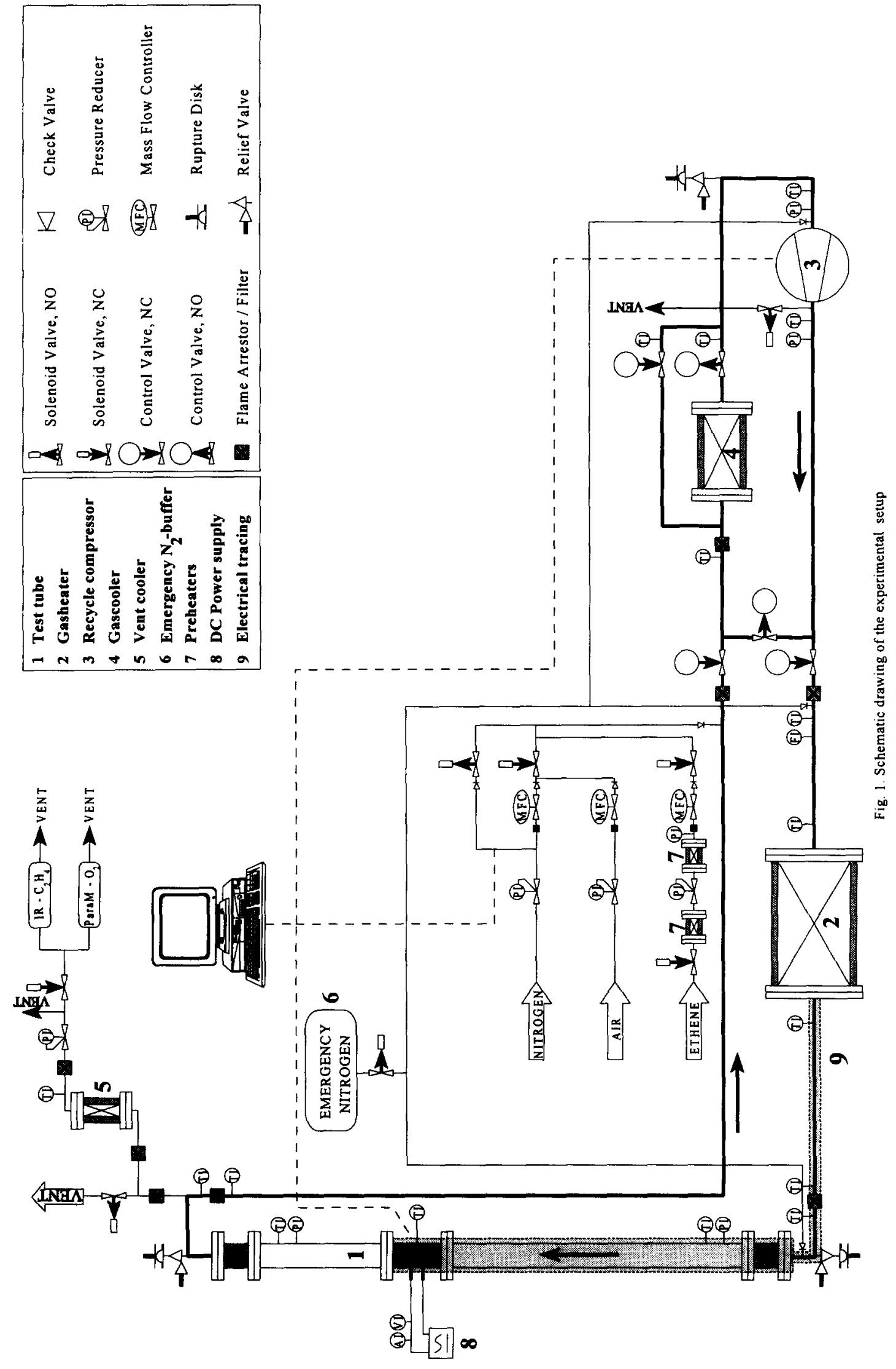
Moreover it is known that some industrial processes are operated within the known flammability limits. During the Second World War the Germans produced ethyne at pressures up to 50 bar, whereas stagnant ethyne is self explosive also above 2 bar. It has also been stated that an oxidation process can be operated with an explosive gas mixture, for instance the partial oxidation of butene to maleic anhydride, see Kirk-Othmer (1981).

Zabetakis (1965), Craven and Foster (1966), Gaube et al. (1968) and Chippett (1993) have measured the flammability limit of ethene-air-nitrogen mixtures under variable conditions in stagnant systems. We in this work study experimentally the upper explosion limit of ethene-air-nitrogen mixtures with a hot surface as ignition source under conditions of flow. Experiments are performed with varying gas compositions, pressures, temperatures, gas flow rates and hot spot size and temperatures. A large test installation has been built to do experiments at equal conditions as in the commercial oxidation process.

\section{EXPERIMENTAL SET-UP}

A large test installation has been located in a concrete bunker and is controlled from the outside. The experimental conditions are similar as in the commercial partial oxidation process for producing ethene oxide. Maximum operating conditions are shown in Table 1. Fig. 1 shows a schematic drawing of the experimental installation. Three different stainless steel explosion tubes are available with inner diameters of 21,50 and $100 \mathrm{~mm}$. Each tube is $3.0 \mathrm{~m}$ long and is placed vertically. The first part of the tube is $2.0 \mathrm{~m}$ long and serves to build up a constant turbulent velocity profile. After this inlet part, the gas passes the ignition source, the hot wire, which will be described later. The direction of the gas flow can be either upwards or downwards, but all data presented here are for upward flow in the $21 \mathrm{~mm}$ explosion tube.

\begin{tabular}{lll}
\hline Tube length & 3.0 & $\mathrm{~m}$ \\
Tube diameters & $21,50,100$ & $\mathrm{~mm}$ \\
Gas composition: & & \\
$\quad$ Ethene & 25 & $\mathrm{vol} \%$ \\
$\quad$ Oxygen & $8-16$ & $\mathrm{vol} \%$ \\
$\quad$ Nitrogen & $59-67$ & $\mathrm{vol} \%$ \\
Maximum pressure & 20 & $\mathrm{bar}$ \\
Maximum temperature & 300 & ${ }^{\circ} \mathrm{C}$ \\
Maximum gas velocity: & & \\
21 mm tube & 20 & $\mathrm{~m} / \mathrm{s}$ \\
$50 \mathrm{~mm}$ tube & 4 & $\mathrm{~m} / \mathrm{s}$ \\
$100 \mathrm{~mm}$ tube & 1 & $\mathrm{~m} / \mathrm{s}$ \\
\hline
\end{tabular}

Table 1. Range of operating conditions in the experimental installation

The electrically heated ignition wire is placed either horizontally or vertically in the explosion tubes. The length of the wire is $40 \mathrm{~mm}$ in the vertical position and $21 \mathrm{~mm}$ in the horizontal position. The wire material is Kanthal Al - an alloy of mainly $\mathrm{Fe}, \mathrm{Cr}$ and $\mathrm{Al}$ - and the diameter $0.6 \mathrm{~mm}$. The wire is connected at both ends to stainless steel rods of $3.0 \mathrm{~mm}$ diameter for the DC power supply. A window of quartz glass is installed in the tube wall in such a way that the middle of the wire can be observed. In front of this window a video camera or an optical pyrometer can be placed, see Fig. 2. In most cases a pyrometer is used, to measure the surface temperature of the wire between 700 and $1200{ }^{\circ} \mathrm{C}$. See Siccama (1993) for a detailed description of the explosion tube and the ignition source.

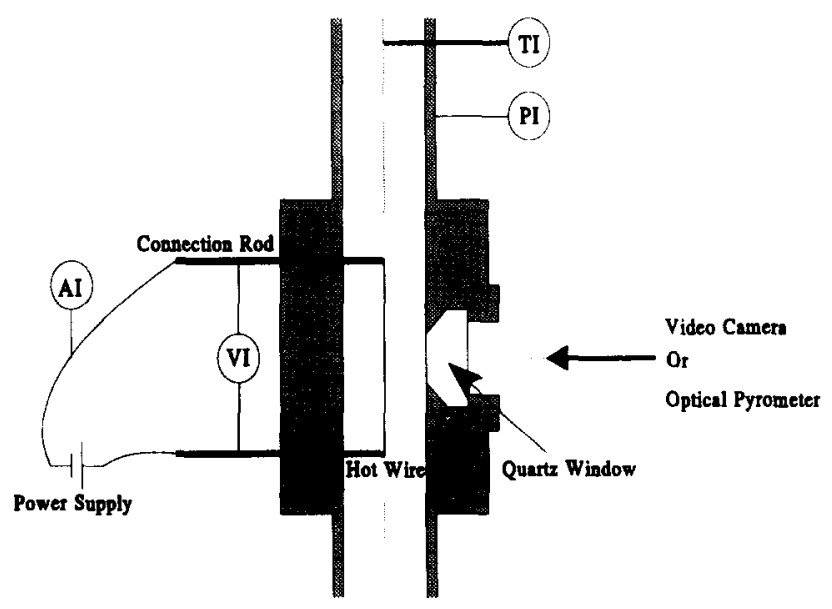

Fig.2. Schematic drawing of the ignition section 
A Hofer double acting piston compressor is used to recycle the gas mixture. By recirculating part of the compressed gas, the velocity in the explosion tubes is controlled. The maximum gas flow capacity is $30 \mathrm{~m}^{3} / \mathrm{hr}$ at the actual pressure and temperature. The compressor is oil-free, to avoid pollution of the gas mixture and pre-ignition. The maximum allowable pressure and temperature of the compressor is 25 bar and $150^{\circ} \mathrm{C}$ respectively.

Flame arrestors have been placed at both ends of the explosion tube to prevent flame propagation to other parts of the installation. At crucial places in the installation additional flame arrestors have been placed. For the case of a detonation, the installation has been protected by relief valves and rupture disks, with a bursting pressure of 40 bar, which have been placed at both ends of the explosion tubes and at the inlet of the recycle compressor.

Experiments can be performed at increased gas temperatures. In that case the gas from the outlet of the compressor is heated before it enters the explosion tube. In a Sinus-Aben oil-gas heat exchanger with a total capacity of $20 \mathrm{~kW}$ the gas is heated by a thermal oil, which itself is heated electrically and circulated. With thermal oil no local high temperatures can occur, so local ignition sources are avoided. The maximum oil temperature is $350{ }^{\circ} \mathrm{C}$. The tubing from the outlet of the heat exchanger to the explosion tube and the explosion tube itself are traced with electrical heating tape with a total capacity of $5 \mathrm{~kW}$ and also a maximum temperature of $350{ }^{\circ} \mathrm{C}$. The maximum gas temperature at which experiments can be performed is limited to $300{ }^{\circ} \mathrm{C}$. Thermocouples are placed at various locations in order to observe whether slow oxidation of ethene occurs and releases heat locally.

Since the compressor can be damaged by gas temperatures above $150{ }^{\circ} \mathrm{C}$, the recycle gas is cooled in a gas cooler before the inlet of the compressor. The total cooling capacity is about $20 \mathrm{~kW}$.

The entire installation is controlled and all data are collected by a Data Acquisition Control Unit (DACU) of Hewlett Packard and send to a HP computer. If a measured value exceeds a present maximum value, all valves are switched to their fail-safe position and the installation is flushed with nitrogen from an emergency buffer.

\section{Experimental procedure}

Before an experiment, the installation is flushed with nitrogen to assure that all ethene and oxygen has been removed. The flows are set by Brooks thermal mass flow controllers. After flushing, ethene is mixed with nitrogen and fed to the installation. Heaters are placed in the ethene supply line to counteract the large Joule-Thompson effects during reduction of the ethene pressure from $50 \mathrm{bar}$ in the storage tanks. The ethene concentration is measured on-line in the vent with an IR-analyser of Servomex. In all experiments the ethene concentration is $25 \mathrm{Vol} \%$, which is controlled automatically with the mass flow controllers. After setting the ethene concentration air is added to the system. Gases have to be introduced in this order, to avoid explosive gas compositions. The air is mixed into the ethene-nitrogen mixture in the gas mixing section and taken up in the recycle stream. The oxygen concentration is also measured on-line in the vent gas with a paramagnetic oxygen analyser of Servomex and controlled automatically.

As soon as the gas composition is constant, the pressure in the installation is increased via the back pressure controller in the vent line. The vent is cooled to protect the back pressure controller and the gas analysers.

After the gas composition and the pressure are stabilised, the velocity in the explosion tube is adjusted to its set-point. The gas velocity is measured by a Höntsch propeller measuring probe, placed in the recycle line.

The temperatures are measured at different positions with $0.5 \mathrm{~mm}$ K-type thermocouples. The temperature in the explosion tube is controlled by chancing the power supply to the electrical tracing and the inlet temperature of the compressor via the cooler.

After stabilisation of the concentrations, pressure, gas temperature and velocity in an experiment, the wire is heated electrically for $30 \mathrm{~s}$ by a Hewlett Packard computer controlled DC power supply. The pressure and the temperature in the tube, the temperature of the hot wire and the voltage drop over the wire in this period are measured continuously with a rate of $100 \mathrm{~Hz}$. The gas mixture is considered to be ignited, if the pressure rises suddenly more than 0.2 bar or the temperature in the tube suddenly more than $200^{\circ} \mathrm{C}$. In case of ignition the power supply is switched off and all valves are automatically set in their fail-safe position. Simultaneously the installation is flushed with nitrogen. This also suppresses the built up of soot, which is always formed in experiments at the upper explosion limits with ethene in excess. If the pressure or the temperature does not change during the $30 \mathrm{~s}$ heating period of the wire, the mixture is considered to be non explosive. In that case the power supply is switched off and the experiment terminated without flushing with nitrogen. After restabilisation the experiment is repeated with a higher power supply to the wire or other initial conditions.

\section{RESULTS AND DISCUSSION}

Under all experimental conditions three different phenomena are observed, see Fig. 3. There are regimes with no or negligible reaction, with a local reaction around the hot wire and with ignition followed by flame propagation. At low power supply rates to the wire, the temperature of the wire remains low and the reaction between oxygen and ethene is negligible. Increasing the power supply to the wire causes higher wire temperatures and the gas around the wire starts to react and to release heat. As a result of this extra heat generation around the wire, the temperature of the wire is considerably higher then at a constant and high value of the power supply without reaction. Similar results have been obtained by Laurendeau and Caron (1982) and Cho and Law (1986). 
At low oxygen concentration this reaction remains localised around the wire resulting in a so-called local reaction. Increasing the oxygen concentration results in a higher reaction rate and the reaction heat produced can not be completely removed anymore. The surrounding gas starts to heat up and the reaction propagates through the flowing gas. This is characterised by flame propagation and can be observed by a sudden pressure or temperature rise. The boundary between local reaction and explosion results in a steep line with negative slope, shown in Fig. 3 . We define the intersection of this steep line with the horizontal line representing the minimum power supply as the 'explosion point', see Siccama and Westerterp (1993).

Similar results have been observed by Coward and Quest (1927). For ignition of natural gas-air mixtures by heated metal bars, where below a critical temperature of the metal bar no reaction could be observed. At higher temperatures local reaction or an explosion was initiated, depending on gas composition.

Williams et al. (1991) studied ignition, extinction, and autothermal behaviour of homogeneous and heterogeneous oxidation reactions with air over resistively heated polycrystalline platinum foils and described the phenomena as a function of the combustible concentration and the temperature of the hot spot.

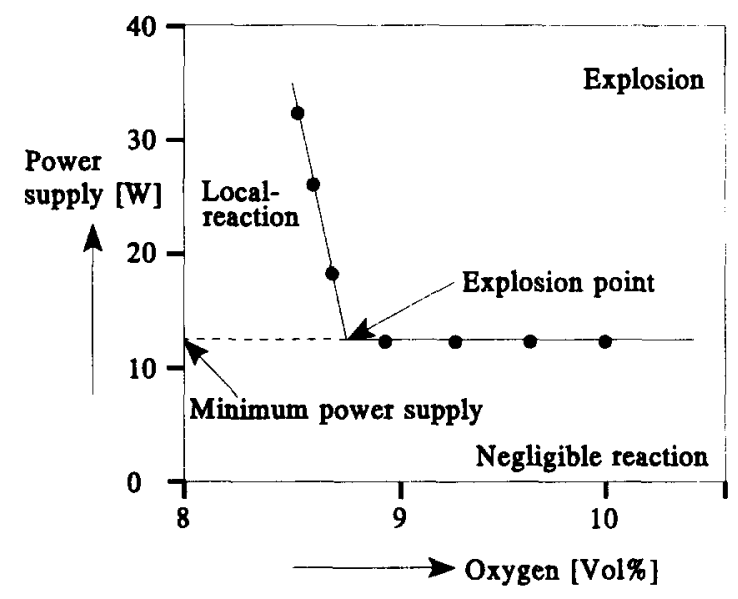

Fig. 3. Ignition phenomena as a function of power supply and oxygen concentration

We obtain similar results; Unfortunately in most cases we could not measure the wire temperature at the minimum power supply rate, because in that case the temperature is below the detection limit of $700^{\circ} \mathrm{C}$ of our pyrometer.

Influence of the gas flow rate and pressure

To investigate the effect upon the flammability limits of the gas flow and pressure, experiments have been performed at varying gas flow rates and at pressures of 5 and 10 bar in upflow. Results are shown in Fig. 4.

When the gas flow rate is increased, it becomes more cifficult to ignite the gas mixture. Higher power supply rates to the wire are required to reach the same wire surface temperature due to the increased heat removal by forced convection. The ignition temperature of the wire can not be measured, as mentioned before. Above $2.5 \mathrm{~m} / \mathrm{s}$ it is not possible anymore to ignite the gas mixture with the $0.6 \mathrm{~mm}$ wires, because such high power supply rates are necessary that the wires melt. As can be seen in Fig. 4. the oxygen concentration at the explosion point increases linearly with gas velocity. This can be explained as follows; Once the mixture is ignited, a flame propagates through the tube. In this case the heat generated by the chemical reaction in the flame is greater than the heat removal from the flame surface to the surrounding gas. When the gas flow rate is increased, also the heat removal to the unburnt gas is increased, while the heat generation remains constant. To counterbalance the increased heat removal rate, higher reaction rates and therefore higher oxygen concentrations are required. 


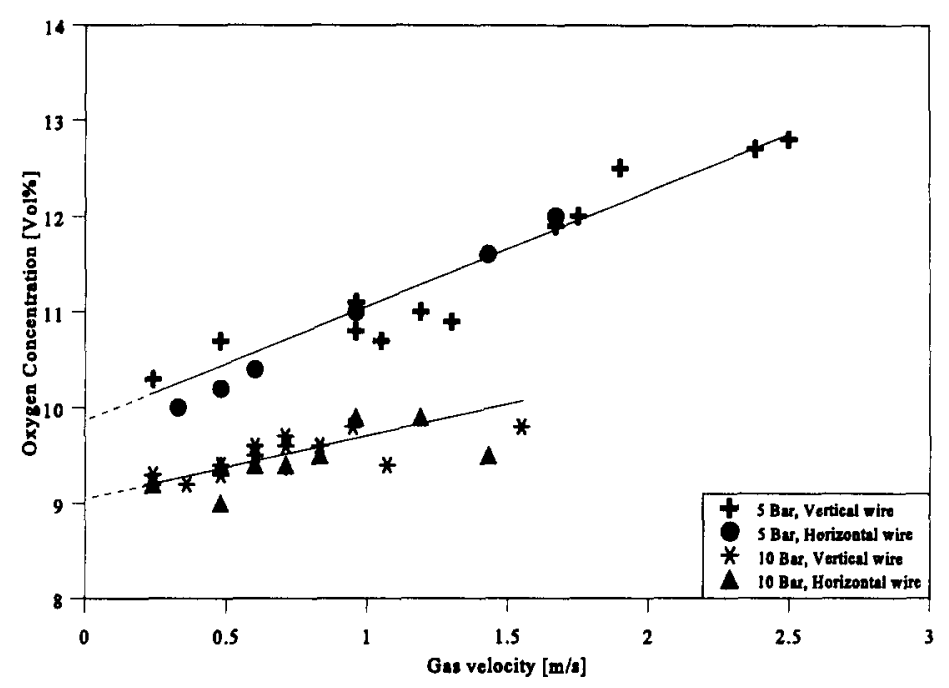

Fig. 4. Explosion points as a function of the gas velocity; $\mathrm{C}_{2} \mathrm{H}_{4}=25 \mathrm{Vol} \%, \mathrm{~T}=298 \mathrm{~K}$

For horizontal wires it is more difficult to ignite the gas mixture, because convective heat removal from a horizontal wire is better than from a vertical one. However, the oxygen concentration at the explosion point is equal for both wire configurations, because once a gas is ignited, flame propagation depends only on heat generation and heat removal to the unburnt gas and no more on the ignition source.

An increase in pressure results in a decrease in the oxygen concentration at the explosion point, because at an increased concentration also the production rate is increased per unit volume.

Flammability limits in stagnant gases can be found by extrapolation in Fig. 4. to zero velocity. The values obtained can be compared to literature data on flammability limits in stagnant ethene-air-nitrogen mixtures at different pressure and temperature. We find oxygen concentration at the explosion point of $9.9 \mathrm{vol} \%$ at 5 bar and $9.0 \mathrm{vol} \%$ at $10 \mathrm{bar}$. This agrees with the results of Fiumara and Cardillo (1976), Gaube et al. (1968) and Craven and Foster (1966). Fiumara and Cardillo found an upper limit of 8.4 vol\% oxygen at 10 bar. Gaube et al. measured the explosion limits of ethene-oxygennitrogen mixtures at 1 and 26 bar and at temperatures up to $300^{\circ} \mathrm{C}$. They used different ignition sources and found at room temperature an oxygen concentration at explosion of 15 vol\% at 1 bar and of 10 vol\% at 7 bar. Craven and Foster found an oxygen concentration at explosion of $11.4 \mathrm{vol} \%$ at 3 bar and $9.1 \mathrm{vol} \%$ at 9 bar.

\section{Influence of the gas flow rate and gas temperature}

The operating temperature to oxidize ethene is typically around $240{ }^{\circ} \mathrm{C}$. It is therefore important to investigate the effect of temperature on the flammability limits of diluted ethene-oxygen mixtures. We performed experiments at gas temperatures of $25,150,225$ and $300^{\circ} \mathrm{C}$ with vertical wires: results are shown in Fig. 5 . An increase in temperature results in a linear decrease in the oxygen concentration at the explosion point. Similar results in stagnant media are found by many other researchers.

Lovachev et al. (1973) gave an excellent review of the effect of temperature on flammability limits. Most results showed a linear dependence between the limiting concentration and the temperature, both in rich and lean mixtures. This linear dependence could be explained by assuming that propagating flames reach a constant flame temperature, independent of the temperature of the unburnt gas. At higher gas temperatures less heat has to be produced to reach this constant flame temperature and as a result the oxygen concentration at explosion point is decreased.

The following relation could be obtained for the concentration oxygen at the upper flammability limit at constant flame temperature;

$$
U_{O_{2}, 5}=U_{O_{2}, 0}-\frac{U_{o_{2}, 0}}{\left(T_{\text {Const. }}-T_{0}\right)} *\left(T-T_{0}\right)
$$

The lines in Fig. 5 represent Eq. 1. with a flame temperature of $1100^{\circ} \mathrm{C}$, according to Zabetakis (1965). These lines fit the data fairly well. 


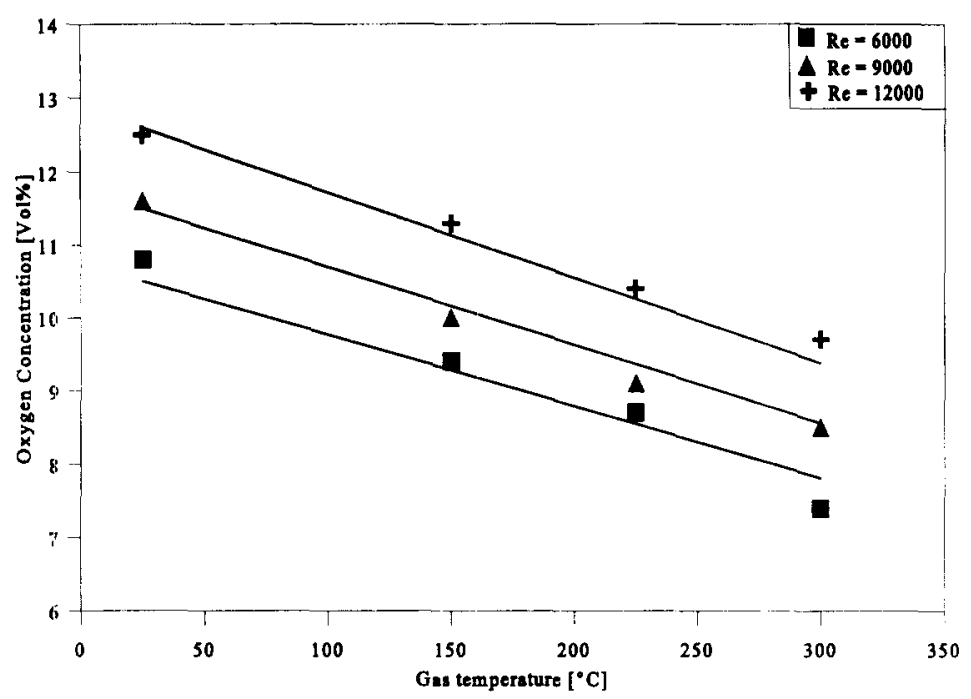

Fig. 5. Explosion points as a function of the gas temperature; $\mathrm{C}_{2} \mathrm{H}_{4}=25 \mathrm{Vol} \%, \mathrm{P}=5 \mathrm{Bar}$

We expected that at higher gas temperatures it would be easier to ignite the gas mixtures. However, as can be seen in Fig. 6, the power supply to the wire at the explosion point is not significantly influenced by the initial gas temperature. This means that the heat transfer from the wire to the gas is constant and that there is a constant temperature difference between the wire and the gas. The result is that at higher initial gas temperatures the temperature of the wire is higher.

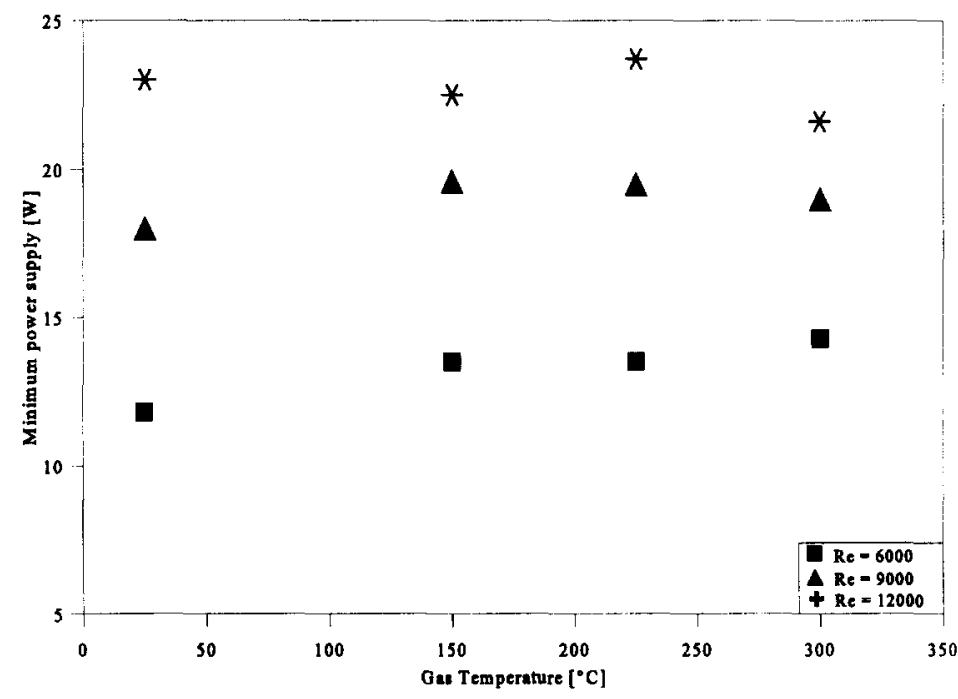

Fig. 6. Minimum power supply at the explosion point as a function of gas temperature; $\mathrm{C}_{2} \mathrm{H}_{4}=25 \mathrm{Vol} \%, \mathrm{P}=5 \mathrm{Bar}$

\section{CONCLUSIONS}

Flammability limits of ethene-air-nitrogen mixtures have been studied in a large test installation under flow conditions. Experiments have been performed at the upper limit with ethene in excess, at pressures of 5 and 10 bar, gas temperatures up to $300{ }^{\circ} \mathrm{C}$ and gas velocities from 0.2 to $2.5 \mathrm{~m} / \mathrm{s}$. As ignition source an electrically heated wire is used, placed horizontally or vertically.

In all experiments three different regimes have been observed. A negligible reaction region occurs at low power supply rates to the wire, independent of the oxygen concentration: the temperature of the wire is not high enough to initiate a reaction or explosion. At higher power supply rates to the wire and thus at higher wire temperatures either a local reaction or an explosion occurs, depending on the oxygen concentration. The boundary between these two regimes can be explained by the balance between the heat produced by the chemical reaction and the heat removal by convection to the flowing gas. 
The critical oxygen concentration required for an explosion at 5 bar and $25^{\circ} \mathrm{C}$ increases from 10 to 13 vol\% oxygen for a velocity increase from 0.2 to $2.5 \mathrm{~m} / \mathrm{s}$. For 10 bar an increase from 9 to 10 vol\% oxygen is observed for a velocity increase from 0.2 to $1.7 \mathrm{~m} / \mathrm{s}$.

No influence of the wire orientation has been observed. Higher gas temperatures result in a decrease of the oxygen concentration required for an explosion. The results can be fitted by assuming a constant flame temperature of $1100^{\circ} \mathrm{C}$. Compared to flammability limits measured in stagnant media, the flammability limits under conditions of flow and with hot spots as ignition sources are completely different. The flammability limits shift to higher oxygen concentrations. In practise this may mean that partial oxidation reactions can safely be operated at higher oxygen concentrations and be more efficiently, provided gas flow rates are kept high.

\title{
ACKNOWLEDGEMENTS
}

These investigations were supported by the Netherlands' Foundation for Chemical Research (SON) with financial aid from the Netherlands' Technology Foundation (STW). It forms part of a project initiated by the University of Twente, Dow Benelux, N.V., Terneuzen and Shell Internationale Chemie Mij., B.V., Den Haag, the Netherlands. The authors wish to thank A.A. Tates, M. Cos and R. van Zinderen Bakker for performing part of the experimental work, and G.H. Banis, P.J. Flanagan, F. ter Borg, K. van Bree and A.H. Pleiter for technical support, and further J.M. Wigman and H. van den Berg of Dow and J.P. van der Linden, M. van der Schoot and G.H. Geertsema of Shell for their guidance and support.

\author{
NOTATION \\ $\mathrm{U} \quad$ Volume percentage at upper flammability limit \\ T Temperature, ${ }^{\circ} \mathrm{C}$ \\ $\mathrm{d}_{\mathrm{t}} \quad$ Tube diameter, $\mathrm{m}$ \\ u Velocity averaged over cross section, $\mathrm{m} / \mathrm{s}$
}

Greek letters

$\eta \quad$ Dynamic viscosity, Pa $s$

$\rho$ Density, $\mathrm{kg} / \mathrm{m}^{3}$

Dimensionless groups

$\operatorname{Re} \quad$ Reynolds number $\left(=\rho \mathrm{de}_{\mathfrak{t}} / \eta\right)$

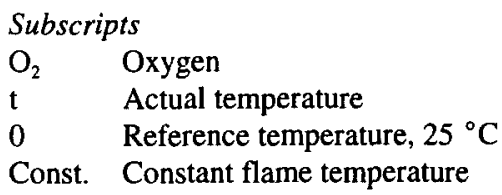

\section{REFERENCES}

Chippett, S., 1994, Flammability measurements in a turbulent flow system, 28th AICHE Loss Prev. Symp., April 17-21, Session: Materials Reactivity and Flammability, Paper 8b.

Cho, P., Law, C.K., 1986, Catalytic ignition of fuel/oxygen/nitrogen mixtures over platinum, Comb. Flame, 66, 159-170.

Coward, H.F., Guest, P.G., 1927, Ignition of natural gas-air mixtures by heated metal bars, J. Am. Chem. Soc., 49, 2479. 2486.

Craven, A.D., Foster, M.G., 1966, The limits of flammability of ethylene in oxygen, air and air-nitrogen mixtures at elevated temperatures and pressures, Comb. Flame, 10, 95-100.

Cutler, D.P., 1974, The ignition of gases by rapidly heated surfaces, Comb. Flame, 22, 105-109.

Detz, C.M., 1976, Treshold conditions for the ignition of acetylene gas by a heated wire, Comb. Flame, 26, 45-55.

Fiumara, A., Cardillo, P., 1976, Influenza della temperatura e della pressione sull'infiammabilita dell'etilene, La Rivista dei Combustibili, 30, No. 9-10, 296-300.

Gaube, J., Grosse-Wortmann, H., Simmrock, K.H., 1968, Explosionsgrenzen der systeme $\mathrm{C}_{2} \mathrm{H}_{4} / \mathrm{O}_{2} / \mathrm{N}_{2}$ bis 26 at und $300{ }^{\circ} \mathrm{C}$ sowie $\mathrm{C}_{2} \mathrm{H}_{4} / \mathrm{H}_{2} / \mathrm{O}_{2} / \mathrm{N}_{2}$ bei 1 at und $20{ }^{\circ} \mathrm{C}$, Chem. Ing. Techn., 40, 660-662.

Kirk-Othmer, 1980, Encyclopedia of Chemical Technology, Explosives and Propellants, 9, Wiley, New York.

Laurendeau, N.M., Caron, R.N., 1982, Influence of hot surface size on Methane-Air ignition temperature, Comb. Flame, 46, 213-218.

Leuckel, W., Nastoll, W., Zarzalis, N., 1989, Influence of turbulence on transient premixed flame propagation inside closed vessels, Chem. Eng. Technol., 12, 226-233.

Lewis, B. and von Elbe, G., 1961, Combustion, Flames and Explosions of Gases, Acedemic Press Inc., New York

Lovachev, L.A., Babkin, V.S., Bunev, V.A., V'Yun, A.V., Krivulin, V.N., Baratov, A.N., 1973, Flammability limits: An invited review, Comb. Flame, 20, 259-289. 
Siccama, N.B., Westerterp, K.R., 1993, The explosion region becomes smaller under flow conditions: The ignition ethene-air mixtures with a hot surface, Ind. Eng. Chem. Res., 32, 1304-1314.

Siccama, N.B., 1993, Explosions in flowing combustible gas mixtures, PhD Thesis, The University of Twente, Enschede, The Netherlands.

Ullmann, 1981, Encyklopädie der technischen Chemie, 4. Auflage, Verlag Chemie, Weinheim, 20, 308.

Watanabe, F., Mitsuhata, M., Kumazawa, T., 1983, Process for production of ethylene oxide, United States Patent, 4,376,209.

Williams, W.R., Stenzel, M.T., Song, X., Schmidt, L.D., 1991, Bifurcation behaviour in homogeneous-Heterogeneous combustion. I:Experimental results over platinum, Comb. Flame, 84, 265-276.

Zabetakis, M.G., 1965, Flammability characteristics of combustible gases and vapours, PhD thesis, Dept. of the interior, Bureau of mines, Washington, U.S. 